\title{
Chromosome 14q loss defines a molecular subtype of clear-cell renal cell carcinoma associated with poor prognosis
}

\author{
Federico A Monzon ${ }^{1,2}$, Karla Alvarez ${ }^{1}$, Lief Peterson ${ }^{3}$, Luan Truong ${ }^{1}$, Robert J Amato ${ }^{4}$, \\ Joan Hernandez-McClain ${ }^{4}$, Nizar Tannir ${ }^{5}$, Anil V Parwani ${ }^{6}$ and Eric Jonasch ${ }^{5}$ \\ ${ }^{1}$ Department of Pathology, The Methodist Hospital Research Institute, Houston, TX, USA; ${ }^{2}$ Department of \\ Pathology, Weill-Cornell Medical College, New York, NY, USA; ${ }^{3}$ Center for Biostatistics, The Methodist \\ Hospital Research Institute, Houston, TX, USA; ${ }^{4}$ Division of Oncology, The University of Texas Medical \\ School, Houston, TX, USA; ${ }^{5}$ Department of Genitourinary Oncology, The University of Texas MD Anderson \\ Cancer Center, Houston, TX, USA and ${ }^{6}$ Department of Pathology, University of Pittsburgh Medical Center, \\ Pittsburgh, PA, USA
}

\begin{abstract}
Loss of chromosome 14 has been associated with poor outcomes in clear-cell renal cell carcinoma. Expression of $\mathrm{HIF} \alpha$ isoforms has been linked to distinct molecular phenotypes of clear-cell renal cell carcinoma. We hypothesized that chromosome 14 loss could lead to a decrease in HIF1 $\alpha$ levels, as its gene (HIF1A) resides in this chromosome. We analyzed 112 archival clear-cell renal cell carcinoma tumor specimens with 250K SNP microarrays. We also evaluated expression of HIF $\alpha$ isoforms by qPCR and immunohistochemistry in a subset of 30 patients. Loss of chromosome $14 q$ was associated with high stage (III-IV, $P=0.001$ ), high risk for recurrence $(P=0.002$, RR $2.78(1.506-5.153))$ and with decreased overall survival $(P=0.030)$ in non-metastatic clear-cell renal cell carcinoma. HIF1 $\alpha$ mRNA and protein expression was reduced in specimens with loss of $14 q(P=0.014)$ whereas HIF $2 \alpha$ was not. Gain of $8 q$ was associated with decreased overall survival $(P<0.0001)$. Our studies confirm an association between $14 q$ loss and clinical outcome in non-metastatic clear-cell renal cell carcinoma patients and that $8 \mathrm{q}$ gain is a candidate prognostic marker for decreased overall survival and appears to further decrease survival in patients with $14 q$ loss. We have also identified that differential expression of HIF1 $\alpha$ is associated with $14 q$ loss. Further exploration of $8 q$ gain, $14 q$ loss, MYC, HIF1A and EPAS1 (HIF2 $\alpha$ ) as molecular markers of tumor behavior and prognosis could aid in personalizing medicine for patients with clear-cell renal cell carcinoma. Modern Pathology (2011) 24, 1470-1479; doi:10.1038/modpathol.2011.107; published online 1 July 2011
\end{abstract}

Keywords: angiogenesis; chromosomal imbalances; EPAS1; HIF1A; hypoxia-inducible factor; prognosis; renal cell carcinoma

Kidney and upper urinary tract cancers account for $\sim 54000$ cases annually in the United States, and represent $\sim 3.7 \%$ of adult malignancies with more than 13000 annual deaths. ${ }^{1,2}$ Renal cell carcinoma is the most common renal malignancy and nearly $50 \%$ of these patients will eventually develop metastatic disease. Although mortality of renal cell cancer has shown an overall decrease due to early diagnosis and improved surgical techniques, as many as

Correspondence: Dr FA Monzon, MD, Department of Pathology, The Methodist Hospital, 6565 Fannin St, MS205, Houston, TX, USA.

E-mail: famonzon@tmhs.org

Received 12 February 2011; revised 13 May 2011; accepted 18 May 2011; published online 1 July 2011
$20-30 \%$ of surgically treated patients still develop recurrence $^{3}$ and there is no reliable biomarker that can predict metastatic or local recurrence in patients with organ-confined tumors. ${ }^{4}$

The histologic subtypes of renal cell tumors have markedly different 5-year disease-specific survival rates. ${ }^{5}$ However, a significant association between histologic subtype and prognosis has not been confirmed by multivariate analysis, where TNM stage, nuclear grade and necrosis are the best outcome predictors. ${ }^{4,6,7}$ The lack of association between histologic subtypes and prognosis in multivariate analyses ${ }^{8}$ could reflect their intrinsic genetic heterogeneity. For clear-cell renal cell carcinoma, loss of the $p$ arm of chromosome 9, loss of 14q and other non-characteristic copy number alterations are 
seen frequently but not universally. ${ }^{9,10}$ Some of these chromosomal aberrations have been associated with poor prognosis (9p/14q deletions) (Table 2) whereas only one, $5 q$ gain, has been associated with good prognosis. $^{10-14}$ Two recent reports underscore the association between loss of $9 p$ and unfavorable clinical outcome in clear-cell renal cell carcinoma patients. $^{15,16}$

We hypothesize that outcome heterogeneity in clear-cell renal cell carcinoma could be a reflection of its intrinsic molecular heterogeneity. Recent data suggest that levels of hypoxia-inducible factor- $\alpha$ isoforms may identify distinct molecular subtypes of clear-cell renal cell carcinoma. ${ }^{17}$ Gordan et $a l^{17}$ identified two clear-cell renal cell carcinoma subpopulations: HIF $1 \alpha / \mathrm{HIF} 2 \alpha$ codominant with enhanced Akt/mTOR and ERK/MAPK signaling, and HIF $2 \alpha$ dominant with increased c-Myc activity and enhanced proliferation and resistance to replication stress. The gene for HIF $1 \alpha$ resides on chromosome $14 q 23.2$, which is often lost in highgrade clear-cell renal cell carcinoma and associated with poor outcome in surgically treated patients. ${ }^{18}$ In addition, Arai et $a l^{19}$ reported that hierarchical clustering of clear-cell renal cell carcinoma based on patterns of chromosomal imbalances can identify two groups of patients with markedly different outcomes. We hypothesized that genomic differences in chromosomes carrying HIF1 $\alpha$ or HIF $2 \alpha$ genes (HIF1A and EPAS1) may be responsible for these phenotypes and impact patient prognosis. Therefore, we used virtual karyotyping with SNP arrays to explore whether these chromosomal imbalances were associated with outcome in a cohort of clear-cell renal cell carcinoma patients and whether $14 \mathrm{q}$ loss is associated with changes in levels of HIF isoforms.

\section{Materials and methods}

\section{Source of Material}

As part of institutionally review board approved protocols, we obtained archival formalin-fixed paraffin-embedded primary tumor samples from 112 patients with clear-cell renal cell carcinoma treated at the participating institutions. Of these, 28 were stage I-II on diagnosis and 84 were stage III-IV. Twenty-four samples were from patients enrolled in a sorafenib versus sorafenib plus interferon alpha trial and 31 patients with metastatic clear-cell renal cell carcinoma were from a presurgical bevacizumab trial. Design and outcomes of these clinical trials have been previously reported. ${ }^{20,21}$

\section{Virtual Karyotyping}

An area with at least $80 \%$ tumor content was manually microdissected from unstained slides and was analyzed with the Affymetrix 250K Nsp SNP
Genotyping arrays (Affy250KNsp, Affymetrix, Santa Clara, CA, USA) following the modified protocol reported before. ${ }^{22}$ Loss of heterozygosity and copy number estimates were obtained using a publicly available analysis package: Copy Number Analyzer for Affymetrix GeneChip arrays (CNAG v3.0). ${ }^{23}$

\section{Immunohistochemistry}

Tissue microarrays from tumors samples from the bevacizumab trial have been described previously. ${ }^{21}$ Immunohistochemistry stains for HIF $1 \alpha$ and HIF $2 \alpha$ were performed with antibodies NB100-123 (1:1500) and NB100-122 (1:500) (Novus Biologicals, Littleton, $\mathrm{CO}$, USA) respectively, using citrate buffer antigen retrieval and the CSAII Biotin Free Tyramide Signal Amplification System (Dako, Carpinteria, CA, USA) and appropriate secondary antibodies on a Dako Autostainer S3400 with a $60 \mathrm{~min}$ incubation for the primary antibody. Nuclear staining intensity for both proteins was evaluated by a pathologist (FAM) and scores for 3 cores from each sample were averaged.

\section{Transcriptomic Analysis}

RNA was extracted using the RNEasy kit (Qiagen, Valencia, CA, USA). RNA quality was evaluated by OD 260/OD 280 on a spectrophotometer (260/280 ratio $>1.8$ ). Real-time qRT-PCR was performed to determine levels of $H I F 1 A$ and EPAS1 (HIF2A) transcripts in tumor samples. Real-time qPCR assays for HIF1A were performed in the Quantitative Genomics Core Laboratory at The University of Texas Health Sciences Center in Houston, TX, using a publicly available primer set (RTPrimerDB ID: 4048). ${ }^{24}$ For EPAS1 expression, RNA from each sample was subjected to reverse transcription using the High Capacity cDNA Reverse Transcription kit (Applied Biosystems, Foster City, CA, USA) and TaqMan Gene Expression assays for EPAS1 (Hs01026149_m1) and 18S rRNA (Hs03928990_g1) transcripts using the TaqMan Universal PCR Master Mix (Applied Biosystems). Relative expression of transcripts was evaluated with the Miner software. ${ }^{25}$ Data from both $H I F 1 A$ and EPAS1 transcripts were normalized for RNA input with $18 \mathrm{~S}$ rRNA levels.

\section{Statistical Analysis}

Determination of gene expression and protein differences between tumors with and without specific chromosomal alterations was performed by Fisher's exact test. Staining intensity for each marker and marker combinations was correlated with chromosome copy number changes in the same tumors and with the available outcome data. Non-parametric Mann-Whitney tests were used to determine significant differences between staining patterns of tumors with and without specific 
chromosomal alterations using log transformed and mean centered data. Association with outcomes was analyzed with Kaplan-Meir survival analysis (logrank test) and multivariate Cox proportional hazard's model. Patients treated with antiangiogenic agents (sorafenib and bevacizumab) were analyzed as a single cohort in this study.

\section{Results}

\section{Frequency of Chromosomal Imbalances}

As expected in clear-cell renal cell carcinoma, we identified loss of $3 p$ in $99 \%$ of samples; with losses of $14 q$ and $9 p$ being the second and third most frequent chromosomal losses (55 and 54\%, respectively) (Table 1). $5 q$ gain was the most frequent chromosomal gain $(51 \%)$, and gains in $5 p$ and trisomy 7 were seen in 29 and $23 \%$ of tumors, respectively. The frequency of $9 p$ and $14 q$ losses in our tumor population was considerably higher than that seen in unselected patient populations of clearcell renal cell carcinoma ${ }^{10}$ but consistent with that reported in association with high-grade and/or highstage tumors, which comprised $75 \%$ of our tumor specimens. ${ }^{18}$ When we evaluated low-stage (stage I-II) and high-stage (stage III-IV) tumors separately, we identified a statistically significant increase in the frequency of these two chromosomal imbalances in high-stage tumors (Table 1 and Figure 1). Concurrent loss of $9 p$ and $14 q$ was seen in $5 \%$ of low-stage and $21 \%$ of high-stage tumors $(P>0.05)$. Other chromosomal arm imbalances associated with tumor stage are shown in Table 1. When we evaluated the percent aneuploid genome (either by percentage of number of chromosomal arms or percentage of probesets with gain or loss) we confirmed that high-stage tumors have a greater percentage of their genome affected by imbalances, and that this difference is dependent on an increased frequency of chromosomal losses in high-stage tumors (Figure 2). When we grouped non-metastatic tumors at diagnosis (stage I-III) versus metastatic (stage IV), $9 \mathrm{p}$ and $8 \mathrm{q}$ losses were significantly more frequent in stage IV tumors $(P=0.008$ and $P=0.02$, respectively). Given the high frequency of $14 q$ loss in our stage III tumors (and the fact that stage III tumors account for more than half of the stage I-III group, there was no difference in the frequency of this chromosomal lesion when stage IIII and stage IV tumors were compared.

\section{Association of Chromosomal Imbalances with Patient Outcome}

From our 112 clear-cell renal cell carcinoma tumor specimens, 85 patients had associated outcome information (13 stage I, 7 stage II, 20 stage III and 45 stage IV) with a median follow-up of 29 months (range 6 to 101 months). As expected, Kaplan-Meier
Table 1 Frequency of chromosomal imbalances in ccRCC samples $(n=112)$

\begin{tabular}{|c|c|c|c|c|c|c|c|}
\hline \multirow[b]{2}{*}{$\begin{array}{l}\text { Chr. } \\
\text { arm }\end{array}$} & \multicolumn{2}{|c|}{$\begin{array}{c}A l l \\
\text { cCRCC }\end{array}$} & \multicolumn{2}{|c|}{$\begin{array}{c}\text { Stage } \\
I-I I\end{array}$} & \multicolumn{2}{|c|}{$\begin{array}{l}\text { Stage } \\
\text { III-IV }\end{array}$} & \multirow[b]{2}{*}{ P-value } \\
\hline & $\begin{array}{c}\text { Loss } \\
(\%)\end{array}$ & $\begin{array}{c}\text { Gain } \\
(\%)\end{array}$ & $\begin{array}{c}\text { Loss } \\
(\%)\end{array}$ & $\begin{array}{c}\text { Gain } \\
(\%)\end{array}$ & $\begin{array}{c}\text { Loss } \\
(\%)\end{array}$ & $\begin{array}{c}\text { Gain } \\
(\%)\end{array}$ & \\
\hline $1 \mathrm{p}$ & 30 & 1 & 25 & 4 & 32 & & NS \\
\hline $1 q$ & 6 & 11 & 11 & 4 & 5 & 13 & NS \\
\hline $2 p$ & 4 & 5 & & 11 & 6 & 4 & NS \\
\hline $2 q$ & 13 & 9 & & 14 & 16 & 7 & NS \\
\hline $3 p$ & 99 & & 100 & & 98 & & NS \\
\hline $3 q$ & 14 & 13 & 25 & 11 & 11 & 14 & NS \\
\hline $4 p$ & 21 & 1 & 7 & & 25 & 1 & NS \\
\hline $4 q$ & 17 & 1 & 7 & & 20 & 1 & NS \\
\hline $5 p$ & 5 & 29 & 4 & 32 & 6 & 27 & NS \\
\hline $5 q$ & 7 & 51 & & 57 & 9 & 48 & NS \\
\hline $6 p$ & 26 & & 25 & & 26 & & NS \\
\hline $6 q$ & 27 & & 25 & & 27 & & NS \\
\hline $7 p$ & 1 & 26 & & 43 & 1 & 20 & $0.0307^{\mathrm{b}}$ \\
\hline $7 q$ & 3 & 23 & & 36 & 4 & 19 & \\
\hline $8 p$ & 40 & 1 & 14 & & 48 & 1 & 0.0003 \\
\hline $8 q$ & 17 & 13 & 18 & & 16 & 16 & 0.0195 \\
\hline $9 p$ & 54 & 3 & 32 & & 60 & 4 & 0.0152 \\
\hline $9 q$ & 39 & 1 & 18 & & 46 & 1 & 0.0077 \\
\hline $10 p$ & 18 & 1 & 18 & & 18 & 1 & NS \\
\hline $10 \mathrm{q}$ & 24 & 2 & 21 & & 25 & 2 & NS \\
\hline $11 p$ & 12 & 1 & 4 & & 14 & 1 & NS \\
\hline $11 \mathrm{q}$ & 16 & 2 & 11 & & 18 & 2 & NS \\
\hline $12 p$ & 1 & 21 & & 18 & 1 & 22 & NS \\
\hline $12 q$ & 3 & 18 & & 18 & 4 & 18 & NS \\
\hline $13 q$ & 23 & 4 & 7 & 7 & 28 & 4 & 0.0205 \\
\hline $14 q$ & 55 & 1 & 29 & & 64 & 1 & 0.0018 \\
\hline $15 q$ & 18 & 1 & 4 & & 22 & 1 & 0.0228 \\
\hline $16 p$ & 13 & 12 & & 18 & 18 & 9 & 0.0205 \\
\hline $16 q$ & 17 & 9 & 7 & 11 & 20 & 8 & NS \\
\hline $17 p$ & 18 & 4 & 4 & & 22 & 5 & 0.0228 \\
\hline $17 q$ & 12 & 6 & & & 15 & 8 & 0.0358 \\
\hline $18 p$ & 23 & 1 & 4 & & 29 & 1 & $0.0037^{\mathrm{c}}$ \\
\hline $18 \mathrm{q}$ & 24 & & 4 & & 31 & & \\
\hline $19 p$ & 28 & 2 & & 4 & 36 & 1 & $0.0002^{\mathrm{c}}$ \\
\hline $19 \mathrm{q}$ & 24 & 2 & & 4 & 32 & 1 & \\
\hline $20 p$ & 6 & 13 & & 4 & 8 & 16 & 0.0128 \\
\hline $20 \mathrm{q}$ & 4 & 14 & & 7 & 5 & 16 & NS \\
\hline $21 q$ & 11 & 10 & 7 & 7 & 12 & 11 & NS \\
\hline $22 q$ & 10 & 1 & & 4 & 13 & & NS \\
\hline
\end{tabular}

Numbers in bold indicate percentage of cases that are significantly different between stage groups..

${ }^{\mathrm{a}}$ Fisher's exact test.

${ }^{\mathrm{b}}$ Trisomy.

${ }^{\mathrm{c}}$ Monosomy.

analysis showed that overall survival was significantly associated with clinical stage (logrank test $P=0.006$, Figure 3a) and nuclear grade $(P=0.003)$ (Supplementary Figure 1, Table 2). We evaluated all chromosomal imbalances that had statistically different frequencies between low- and high-stage tumors (Table 1) for their association with patient outcome. Loss of $9 p$ showed a trend towards decreased overall survival but did not reach 

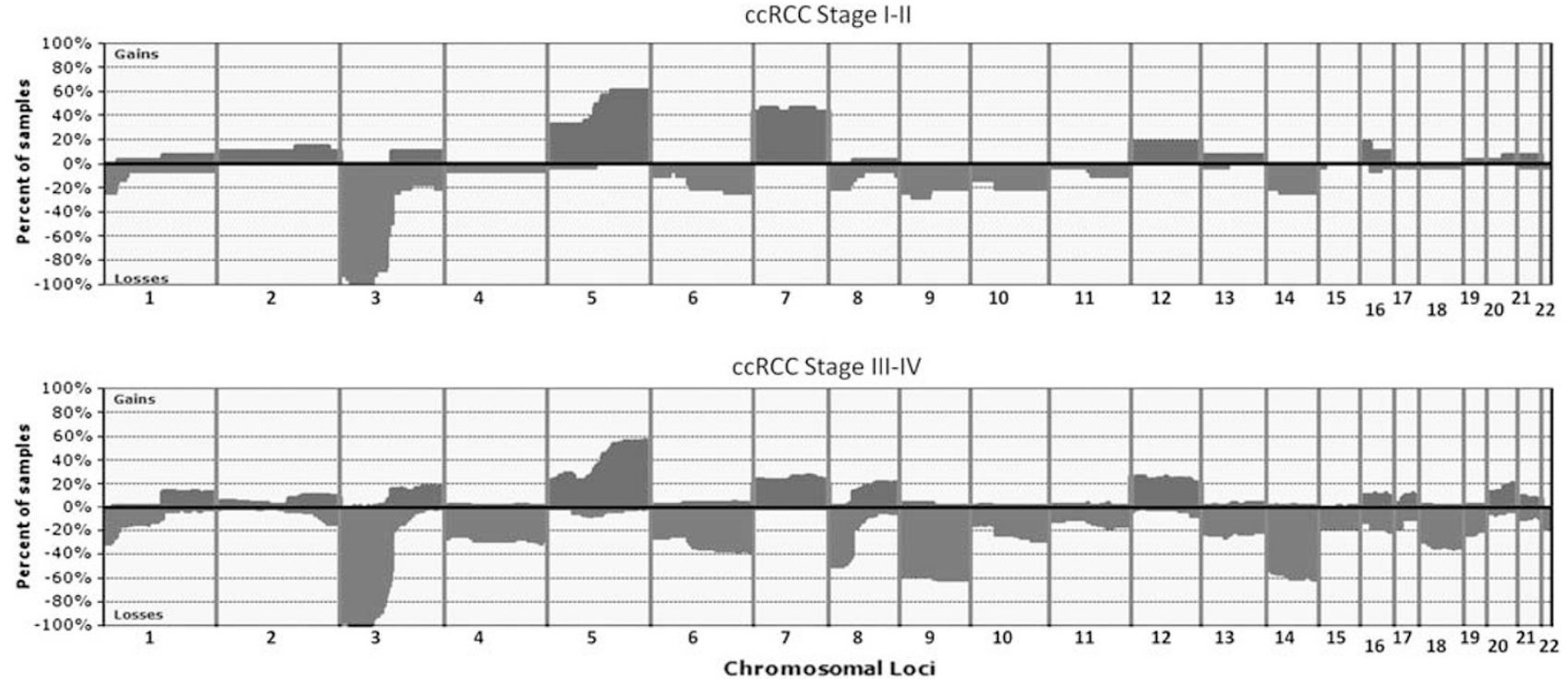

Figure 1 Cumulative frequency of chromosomal lesions in clear-cell renal cell carcinoma $(n=112)$ subdivided by low and high AJCC stage. Gains are indicated as positive values and losses as negative. Note high frequency of chromosome 9 and 14 losses in stage III-IV cases.

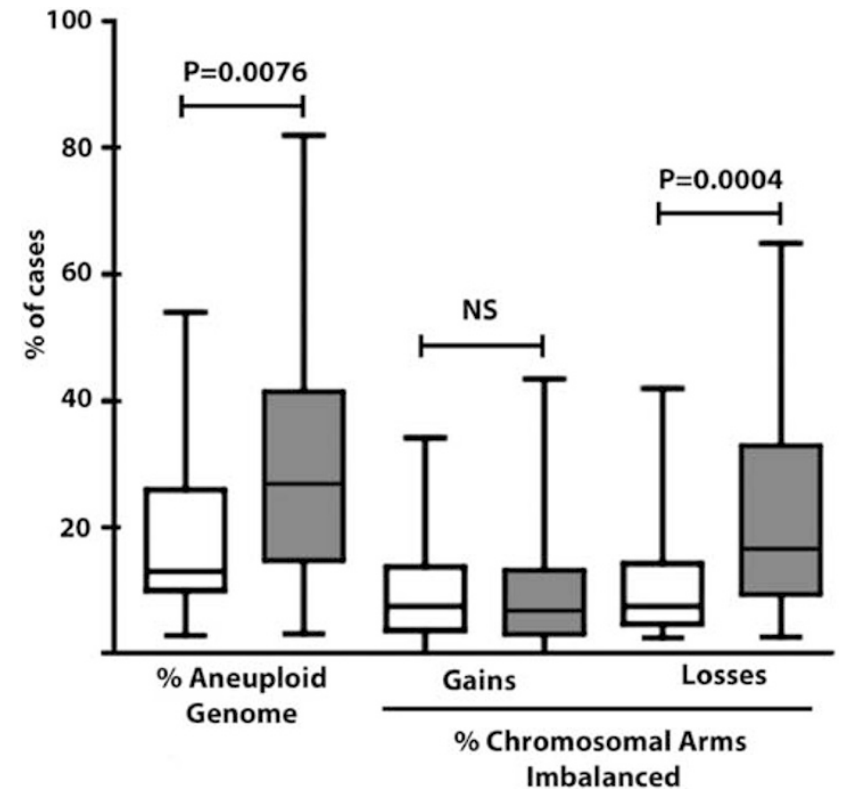

Figure 2 Frequency of chromosomal imbalances in low- (white) and high- (gray) stage clear-cell renal cell carcinoma.

statistical significance $(P=0.23)$ (Figure $3 b) .14 q$ loss was associated with decreased overall survival $(P=0.050)$. The strongest association with decreased overall survival in the full cohort was gain of $8 \mathrm{q}(P<0.0001$, Figure 1e), which was not seen in stage I-II tumors but present in $16 \%$ of stage III-IV patients (Tables 1 and 2). Stratification of patients with $14 \mathrm{q}$ loss based on $8 \mathrm{q}$ status, showed that patients with concomitant $8 \mathrm{q}$ gain and $14 \mathrm{q}$ loss had the worst outcomes $(P=0.0007$, Figure 1f). Eight of the nine patients with the $8 q+14 q-$ tumor genotype died and median overall survival was significantly shorter in patients with this genotype when com- pared with those with $14 \mathrm{q}$ loss only (18 versus 33 months, respectively, $P=0.04$ ). The multivariate Cox regression model analysis showed that stage and $8 \mathrm{q}$ gain were independent predictors of overall survival in our full cohort, whereas $14 \mathrm{q}$ loss and nuclear grade were not independent from stage information. None of the other chromosomal imbalances associated with low-/high-stage showed association with patient outcomes.

When we evaluated only patients with organconfined tumors at diagnosis (stages I-III, $n=40$ ), neither 9p loss nor nuclear grade showed association with overall survival. Fuhrman nuclear grade was associated with recurrence free survival (Logrank, $P=0.010$ ) (Table 2). Loss of $14 \mathrm{q}$ was strongly predictive for recurrence (Fisher's exact test $P=0.0022$, relative risk 2.78 (1.506-5.153)) and showed significantly decreased overall survival $(P=0.030$, Figure 3c), and recurrence free survival $(P=0.006$, Figure $3 \mathrm{~d})$. Gain of $8 \mathrm{q}$ showed a weaker association with overall survival in the organconfined group $(P=0.024)$ and was not associated with recurrence free survival. Multivariate Cox regression analysis showed that neither nuclear grade, $14 q$ loss nor $8 q$ gain were independent from stage information for outcome in the organ confined group (Table 2).

When we evaluated the association of chromosomal imbalances and response to therapy in the patient cohorts that received antiangiogenic therapy, we found a weak association between 14q loss and best response to treatment. Measurable tumor shrinkage (complete of partial response, CR/PR) was seen in $36 \%$ of patients with normal 14q, whereas it was seen only in $10 \%$ of those with $14 \mathrm{q}$ loss (Fisher's exact test, $P=0.11$ ). Tumor shrinkage was observed in $26 \%$ of patients with $9 p$ loss but only in $9 \%$ of patients without $9 p$ loss $(P=0.35)$. Neither $8 q$ 

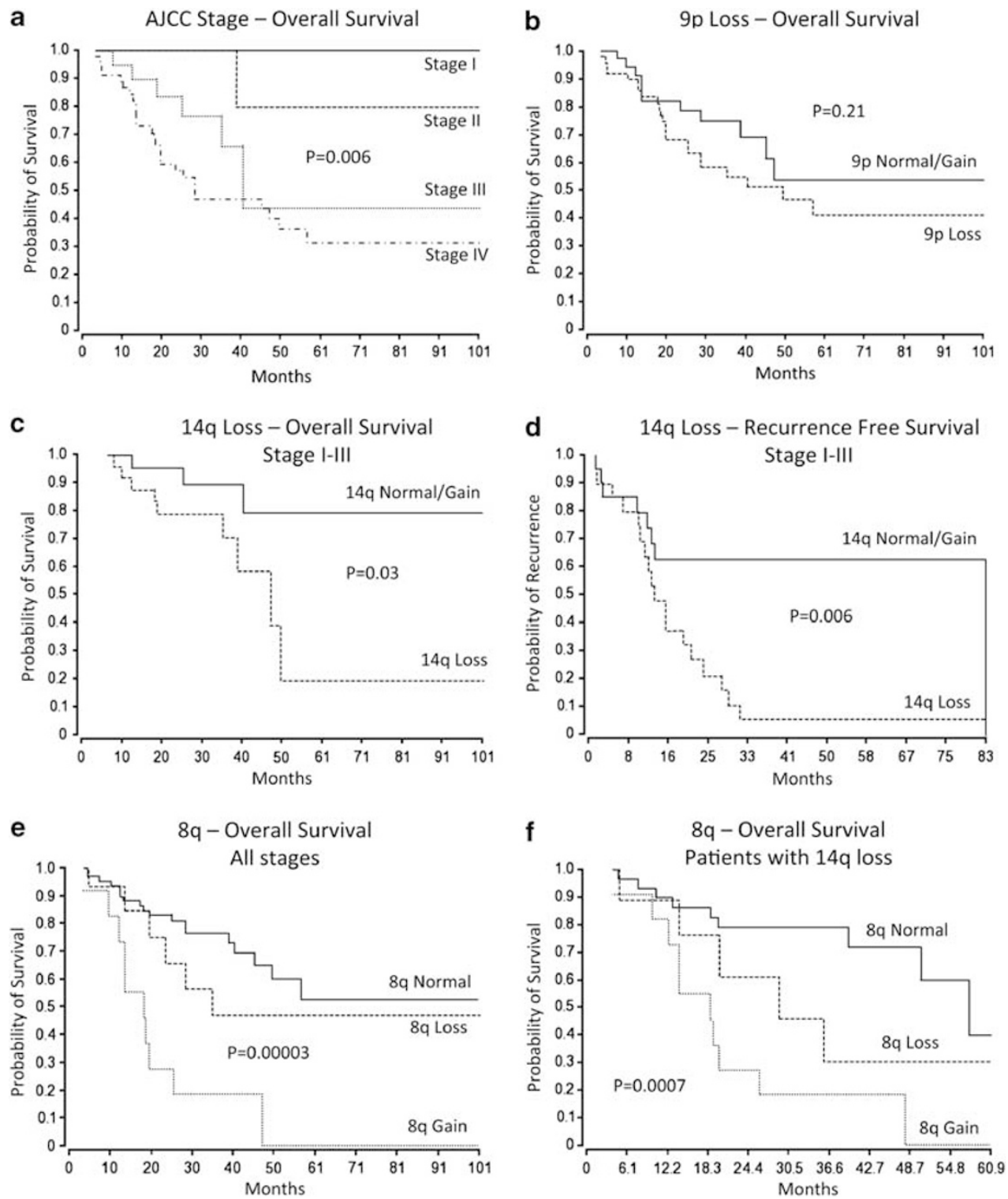

Figure 3 Kaplan-Meier survival analyses in clear-cell renal cell carcinoma patients. (a) Overall survival by AJCC Stage; (b) overall survival by 9 p loss; (c) overall survival by 14q loss; (d) recurrence free survival by 14q loss (stage I-III patients only); (e) overall survival by $8 \mathrm{q}$ status and (f) overall survival by $8 \mathrm{q}$ status in patients with $14 \mathrm{q}$ loss.

gain, 9p loss or $14 \mathrm{q}$ loss showed association with progression free survival or overall survival in the Kaplan-Meier survival analysis (Supplementary Figures 1b-d) or Cox proportional hazards model. However, when we evaluated only patients with $14 \mathrm{q}$ loss, patients with concomitant 14q loss and 8q gain had a significantly shorter survival than those with $14 \mathrm{q}$ loss and either loss or normal $8 \mathrm{q}$ $(P=0.005$, Supplementary Figure 1e).

\section{Association of HIF1 $\alpha$ Levels with Chromosomal Loss}

We evaluated protein and mRNA levels of HIF1 $\alpha$ in specimens from the bevacizumab-treated cohort $(\mathrm{n}=30) .{ }^{20} \mathrm{~A}$ tissue microarray (for immunohisto- chemistry) and/or paraffin blocks (for RNA extraction) were not available for all other samples in the study. HIF $1 \alpha$ protein levels, as measured by immunohistochemistry, showed significant correlation with $14 \mathrm{q}$ status, with a decrease in HIF1 $\alpha$ levels in tumors with loss of $14 \mathrm{q}$ compared with tumors harboring normal $14 \mathrm{q}(P=0.0148$, Student's $t$-test $)$ (Figure 4b). Decreased expression of HIF1A mRNA in samples with $14 \mathrm{q}$ loss was confirmed by qPCR $(0.0019 \pm 0.0014$ versus $0.0036 \pm 0.0032, P=0.038$, Student's $t$-test) (Figure 4a). HIF1 $\alpha$ protein and mRNA levels did not correlate with other chromosomal imbalances (data not shown). Cox regression results indicated that HIF1A mRNA levels are a significant predictor of progression-free survival in the bevacizumab-treated cohort $(\mathrm{HR}=2.29,95 \%$ 
Table 2 Association with outcome in patients with CRCC

\begin{tabular}{|c|c|c|c|}
\hline \multirow[t]{3}{*}{ Variable } & \multicolumn{3}{|c|}{ Overall survival } \\
\hline & \multirow{2}{*}{$\frac{\text { Logrank-univariate }}{\text { P value }}$} & \multicolumn{2}{|c|}{ Cox-multivariate } \\
\hline & & $\mathrm{P}$ value & Relative risk, $95 \%$ CI \\
\hline \multicolumn{4}{|l|}{ All stages } \\
\hline AJCC Stage (I-II versus III-IV) & 0.001 & 0.039 & $9.01,1.19-67.76$ \\
\hline Fuhrman nuclear grade ${ }^{\mathrm{a}}$ & 0.003 & n.s. & \\
\hline $9 \mathrm{p}$ loss & n.s. & & \\
\hline $14 \mathrm{q}$ loss & 0.050 & n.s. & \\
\hline 8q gain & $<0.0001$ & 0.006 & $3.43,1.50-7.83$ \\
\hline \multicolumn{4}{|l|}{ Stages I-III } \\
\hline AJCC Stage (I-II versus III) & 0.022 & 0.075 & \\
\hline Fuhrman nuclear grade ${ }^{a}$ & n.s. & & \\
\hline $9 \mathrm{p}$ loss & n.s. & & \\
\hline $14 \mathrm{q}$ loss & 0.030 & n.s. & \\
\hline $8 q$ gain & 0.024 & n.s. & \\
\hline
\end{tabular}

Recurrence free survival

Logrank-univariate Cox-multivariate

Stages I-III

AJCC Stage (I-II versus III)

Fuhrman nuclear grade ${ }^{\mathrm{a}}$

$9 \mathrm{p}$ loss

$14 q$ loss

0.010

0.005

$4.74,1.57-14.26$

8q gain

n.s.

0.0006

n.s. n.s.

n.s.

n.s.

${ }^{\mathrm{a}}$ Grade I versus grades 3-4.

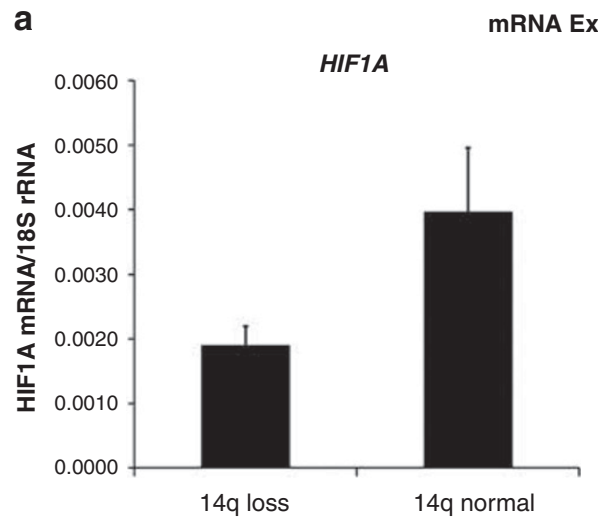

mRNA Expression

b

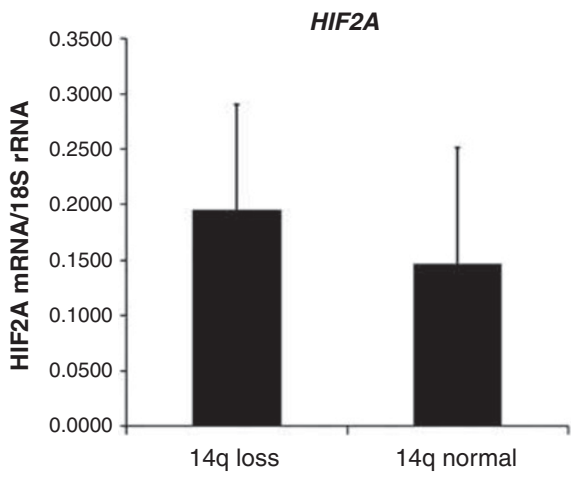

Protein Expression
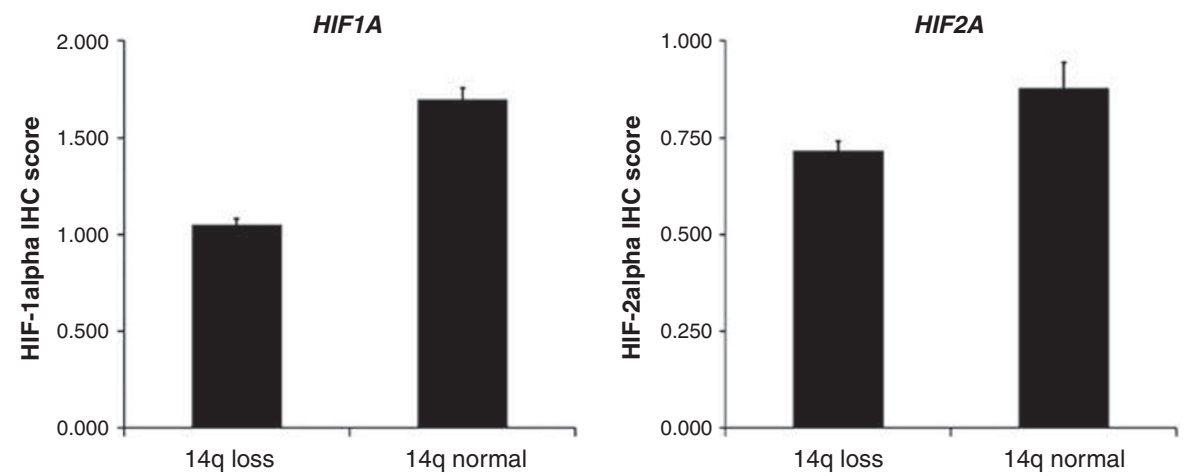

Figure 4 Expression levels (a, mRNA expression; b, protein expression) of HIF1A and EPAS1 (HIF2 $\alpha$ ) in clear-cell renal cell carcinoma tumor specimens with and without $14 \mathrm{q}$ loss. 
$\mathrm{CI}=1.01-5.16, P=0.045)$. However HIF1 $\alpha$ expression as measured by immunohistochemistry was not significantly associated with progression-free survival $(\mathrm{HR}=1.69,95 \% \mathrm{CI}=0.46-6.10, P=0.42)$. Neither protein nor mRNA expression of EPAS1 were associated with $14 \mathrm{q}$ chromosomal imbalance or outcome, consistent with the absence of recurrent loss of 2p21 (EPAS1 locus) (Figure 1). HIF1 $\alpha$ and EPAS1 protein and mRNA levels were not correlated with survival outcomes, consistent with $14 \mathrm{q}$ loss not being predictive for outcome in this cohort of patients with metastatic disease.

\section{Discussion}

A significant issue in the management of patients with clear-cell renal cell carcinoma is the identification of patients that are at higher risk for recurrence. Although mortality of renal cell cancer has shown an overall decrease due to early diagnosis and improved surgical techniques there is no reliable biomarker for prognosis in patients with organconfined tumors (low TNM stage) of which as many as $20-30 \%$ will recur. ${ }^{3,4}$ We and others have hypothesized that the variability in clear-cell renal cell carcinoma patient outcomes might reflect the intrinsic genetic heterogeneity of this tumor. ${ }^{18}$ In this study, we focused on studying the role of $9 p$ and $14 q$ losses, which are two genetic lesions frequently associated with clear-cell renal cell carcinoma progression and on other imbalances with increased frequency in high-stage tumors. Our results show that chromosome $14 \mathrm{q}$ loss is negatively associated with outcome in patients with non-metastatic clear-cell renal cell carcinoma (stages I-III) and indicate that this loss leads to a molecularly distinct phenotype of clear-cell renal cell carcinoma with decreased HIF1 $\alpha$. Furthermore, by using whole genome analysis, we have identified $8 \mathrm{q}$ gain as a genetic lesion also associated with poor outcomes.

In this study, loss of chromosome $14 \mathrm{q}$ was associated with decreased overall survival in clearcell renal cell carcinoma patients, in particular those patients with non-metastatic disease (Figures 2c and d). As described above, the gene for HIF1 $\alpha(H I F 1 A)$ resides in chromosome 14, and this transcription factor is a key regulator of vascular endothelial growth factor A, platelet-derived growth factor $\beta$ and transforming growth factor $\alpha$ expression, all key regulators of angiogenesis and proliferation. ${ }^{26-28}$ Our results further indicate that loss of $14 \mathrm{q}$ leads to a decrease in $H I F 1 A$ mRNA and reduced nuclear HIF $1 \propto$ protein expression and suggest a mechanism for explaining the relationship with poor outcome. Importantly, the association between decreased HIF1 $\alpha$ expression and tumor aggressiveness has been reported previously. ${ }^{29}$ In addition, other investigators have shown that tumors with $14 \mathrm{q}$ loss show decreased expression of several HIF $1 \alpha$ regulated genes (William G Kaelin Jr, personal communication). We hypothesize that loss of $14 \mathrm{q}$ could lead to an imbalance in HIF $1 \alpha / E P A S 1$ activity, and that this imbalance leads to improved tumor cell viability. This hypothesis is also supported by recent work from Gordan et al, who demonstrated that HIF2 $\alpha$ promotes cell cycle progression in hypoxic renal cell carcinoma cell lines and is associated with enhanced $M Y C$ promoter binding, with transcriptional effects on both activated and repressed target genes. In their work, it is shown that when both HIF $1 \alpha$ and HIF $2 \alpha$ are expressed, HIF $1 \alpha$ acts in a dominant negative fashion, and $M Y C$ function is repressed. ${ }^{30}$ Furthermore, Toschi et al observed that downregulation of HIF $1 \alpha$ and HIF $2 \alpha$ occurs through differential regulation of specific mTOR complex components Raptor and Rictor, which in turn have differential effects on downstream targets of S6 kinase and AKT, respectively. ${ }^{31}$ These studies emphasize the distinct function and regulation of the two HIF $\alpha$ isoforms. Increased EPAS1 (HIF2 $\alpha$ ) activity in tumors with decreased HIF $1 \alpha$ could lead to enhanced MYC expression, improving tumor cell viability by altering DNA damage repair mechanisms, and by upregulating various pro-survival pathways downstream of AKT. ${ }^{17}$ The fact that EPAS1 protein and transcript levels were not affected by $14 \mathrm{q}$ loss in our samples supports the hypothesis that an imbalance in HIF isoforms could define a specific clear-cell renal cell carcinoma phenotype with aggressive behavior.

Loss of the $p$ arm of chromosome 9 has been recently been associated with unfavorable clinical outcome in clear-cell renal cell carcinoma patients. ${ }^{13,15}$ Although the genes responsible for this association have not been identified, several potential candidates (such as CDKN2A (p16), CAIX and the interferon genes INFA1/INFB1) reside in this chromosomal region. ${ }^{15}$ Interestingly, in our patient cohort 9p loss was neither associated with recurrence, or response to therapy, but showed a trend towards decreased overall survival. The lack of statistically significant association between 9q loss and survival in our study could be explained by the fact this association has been established in unselected patient populations, with few of the patients showing metastasis at presentation. ${ }^{13,15}$ Recently, La Rochelle et $a l^{16}$ indicated that 9p loss was specifically associated with poor outcome in patients with localized, small renal masses. Our cohort includes a significant proportion of patients with metastatic disease and includes very few patients with small, localized tumors. Therefore, our results and La Rochelle's suggest that 9p does not influence the prognosis of large (advanced) or already metastatic tumors.

We also found that $8 \mathrm{q}$ gain was strongly prognostic for overall survival in clear-cell renal cell carcinoma patients and seems to identify a subgroup of patients with $14 \mathrm{q}$ loss with significantly poor survival. Interestingly, $8 \mathrm{q}$ gain appears to be an early 
event in hepatocellular carcinoma development, ${ }^{32}$ but our data suggests that in clear-cell renal cell carcinoma 8q gain is a genetic abnormality acquired during tumor progression. Previous investigators in clear-cell renal cell carcinoma have postulated $M Y C$ as a candidate target for $8 \mathrm{q}$ amplification; however, data from hepatocellular carcinoma suggest that COPS5 (also known as JAB1) could be responsible for a proliferative advantage in hepatocellular carcinoma. ${ }^{33}$ Interestingly, it has been shown that COPS 5 regulates HIF $1 \alpha$ activity by direct interaction and modulation of its stability. ${ }^{34}$ Thus, both of these $8 \mathrm{q}$ genes are functionally linked to the HIF pathway; MYC as a downstream effector of HIF $2 \alpha$ as described above and COPS5 as a regulator of HIF1 $\alpha$ function. To our knowledge, this is the first report of the association of $8 \mathrm{q}$ gain with outcome in patients with clear-cell renal cell carcinoma and as such it should be confirmed in other studies. If this association is confirmed, further work on the role of $8 \mathrm{q}$ genes and the MYC pathway in clear-cell renal cell carcinoma tumor behavior is therefore warranted.

Another significant problem in the management of patients with metastatic renal cell carcinoma is demonstration of innate or acquired resistance to molecularly targeted therapies, including those that target angiogenesis. Our results indicate that neither $9 \mathrm{p}$ nor $14 \mathrm{q}$ loss were significantly associated with response to the antiangiogenic agents sorafenib or bevacizumab. Measurable tumor response to these agents was more frequent in patients with normal $9 p$ and $14 q$, but this difference did not reach statistical significance. The lack of significance is either due to the lack of a relationship between these chromosomal abnormalities and clinical outcome in metastatic clear-cell renal cell carcinoma patients treated with antiangiogenic agents, due to limitations in sample size, or due to the fact that we combined two treatment cohorts. Interestingly, the presence of $8 q$ gain seems to separate patients with $14 \mathrm{q}$ loss into different subgroups of patients with markedly different overall survival (Supplementary Figure 1e) when treated with antiangiogenic agents. These findings need to be corroborated in larger cohorts of homogenously treated patients.

Our results suggest a role for $14 q$ loss and HIF $1 \alpha$ levels in clear-cell renal cell carcinoma prognosis, as well as a possible role for the $M Y C$ axis; however, there are a few shortcomings to our findings. First, our analysis is retrospective, and the sample has overrepresentation of high-stage tumors. Given that the association between $14 \mathrm{q}$ loss and outcome was stronger in stage I-III patients, these results need to be corroborated in a larger cohort of patients with no metastasis at diagnosis. Second, we were only able to establish a correlation between $14 \mathrm{q}$ loss and HIF $1 \alpha$ protein and mRNA levels in samples from metastatic clear-cell renal cell carcinoma patients. It is thus necessary to corroborate this association in non-metastatic tumors, which are those in which we identified $14 \mathrm{q}$ to be of prognostic significance.
However, the fact that $14 \mathrm{q}$ loss has been previously associated with high grade/stage tumors and tumorspecific survival, ${ }^{35,36}$ strongly support its role in defining an aggressive tumor phenotype. Third, the association of $14 \mathrm{q}$ loss and outcome does not seem to be independent from stage. This needs to be investigated in a larger cohort with a larger representation of low-stage tumors. However, the fact that 14 loss (and possibly lower levels of HIF $1 \alpha$ ) is coupled tightly with tumor progression strongly suggests that this chromosomal imbalance is part of the pro-survival and pro-metastatic processes that allow clear-cell renal cell carcinoma progression.

In summary, our studies suggest an association between loss of chromosome $14 \mathrm{q}$ and clinical outcome in patients with non-metastatic renal cell carcinoma. Furthermore, we have identified differential expression of HIF $1 \alpha$ associated with this chromosomal imbalance. This association gives support to the notion that there are distinct molecular phenotypes of clear-cell renal cell carcinoma characterized by predominance of different $\mathrm{HIF} \alpha$ subunits. Our results also suggest that genes located in 8q (such as COPS5 and MYC) could be participating in clear-cell renal cell carcinoma's aggressive phenotype. Validation studies to confirm these associations are required, as is the exploration of the role of EPAS1 and MYC modulation as a means to possibly overcome clear-cell renal cell carcinoma aggressiveness. As has been shown with other tumor types such as leukemias and malignant gliomas, molecular classification of disease based on chromosomal alterations has led to better prognostic markers and implementation of more effective targeted therapies. ${ }^{37,38}$ Further exploration of $8 \mathrm{q}$ gain, $14 \mathrm{q}$ loss, HIF1 $\alpha$ and EPAS1 as molecular markers of tumor behavior and prognosis have the potential to aid in personalizing medicine for patients with clear-cell renal cell carcinoma.

\section{Acknowledgements}

We wish to acknowledge the support from the Research Pathology Core at The Methodist Hospital Research Institute for histology services and immunohistochemistry and the Quantitative Genomics Core at the University of Texas Health Science Center in Houston for analysis of HIF1A transcripts (with special thanks to Greg Shipley for helpful suggestions). This study was supported by a Scholars Research Award from The Methodist Hospital Research Institute (FAM) and a grant from the Institute for Personalized Cancer Therapy (IPCT) of the University of Texas MD. Anderson Cancer Center (EJ).

\section{Disclosure/conflict of interest}

The authors declare no conflict of interest. 


\section{References}

1 American Cancer Society. Cancer Facts \& Figures 2008 American Cancer Society: Atlanta 2008.

2 DeVita VT, Hellman S, Rosenberg SA. Cancer, Principles and Practice of Oncology, 6th edn. Lippincott, Williams \& Wilkins: Philadelphia, 2001.

3 Cohen HT, McGovern FJ. Renal-cell carcinoma. N Engl J Med 2005;353:2477-2490.

4 Lam JS, Shvarts O, Leppert JT, et al. Renal cell carcinoma 2005: new frontiers in staging, prognostication and targeted molecular therapy. J Urol 2005;173:1853-1862.

5 Amin MB, Amin MB, Tamboli $\mathrm{P}$, et al. Prognostic impact of histologic subtyping of adult renal epithelial neoplasms: an experience of 405 cases. Am J Surg Path 2002;26:281-291.

6 Delahunt B, Bethwaite PB, Nacey JN. Outcome prediction for renal cell carcinoma: evaluation of prognostic factors for tumours divided according to histological subtype. Pathology 2007;39:459-465.

7 Motzer RJ, Bacik J, Mazumdar M. Prognostic factors for survival of patients with stage IV renal cell carcinoma: memorial sloan-kettering cancer center experience. Clin Cancer Res 2004;10(Pt 2):6302S-6303S.

8 Amin MB, Tamboli P. Impact of histologic subtyping of renal epithelial neoplasms: authors' reply. Am J Surg Path 2003;27:1022-1024.

9 Monzon FA, Hagenkord J, Lyons-Weiler $\mathrm{M}$, et al. Whole genome SNP arrays as a potential diagnostic tool for the detection of characteristic chromosomal aberrations in renal epithelial tumors. Mod Pathol 2008;21:1-10.

10 Yoshimoto T, Matsuura K, Karnan S, et al. Highresolution analysis of DNA copy number alterations and gene expression in renal clear cell carcinoma. J Pathol 2007;213:392-401.

11 Kardas I, Mrozek K, Babinska M, et al. Cytogenetic and molecular findings in 75 clear cell renal cell carcinomas. Oncol Rep 2005;13:949-956.

12 Gunawan B, Huber W, Holtrup M, et al. Prognostic impacts of cytogenetic findings in clear cell renal cell carcinoma: gain of 5q31-qter predicts a distinct clinical phenotype with favorable prognosis. Cancer Res 2001;61:7731-7738.

13 Brunelli M, Eccher A, Gobbo S, et al. Loss of chromosome $9 p$ is an independent prognostic factor in patients with clear cell renal cell carcinoma. Mod Pathol 2008;21:1-6.

14 Moch H, Presti Jr JC, Sauter G, et al. Genetic aberrations detected by comparative genomic hybridization are associated with clinical outcome in renal cell carcinoma. Cancer Res 1996;56:27-30.

15 Klatte T, Rao PN, de Martino M, et al. Cytogenetic profile predicts prognosis of patients with clear cell renal cell carcinoma. J Clin Oncol 2009;27: 746-753.

16 La Rochelle J, Klatte T, Dastane A, et al. Chromosome $9 p$ deletions identify an aggressive phenotype of clear cell renal cell carcinoma. Cancer 2010;116: 4696-4702.

17 Gordan JD, Lal P, Dondeti VR, et al. HIF-alpha effects on C-Myc distinguish two subtypes of sporadic VHL-deficient clear cell renal carcinoma. Cancer Cell 2008;14:435-446.

18 Kim HJ, Shen SS, Ayala AG, et al. Virtual-karyotyping with SNP microarrays in morphologically challenging renal cell neoplasms: a practical and useful diagnostic modality. Am J Surg Pathol 2009;33:1276-1286.

19 Arai E, Ushijima S, Tsuda H, et al. Genetic clustering of clear cell renal cell carcinoma based on array-comparative genomic hybridization: its association with DNA methylation alteration and patient outcome. Clin Cancer Res 2008;14:5531-5539.

20 Jonasch E, Wood CG, Matin SF, et al. Phase II presurgical feasibility study of bevacizumab in untreated patients with metastatic renal cell carcinoma. J Clin Oncol 2009;27:4076-4081.

21 Jonasch E, Corn P, Pagliaro LC, et al. Upfront, randomized, phase 2 trial of sorafenib versus sorafenib and low-dose interferon alfa in patients with advanced renal cell carcinoma: clinical and biomarker analysis. Cancer 2010;116:4-7.

22 Lyons-Weiler M, Hagenkord J, Sciulli CM, et al. Optimization of the Affymetrix GeneChip mapping $10 \mathrm{~K} 2.0$ assay for routine clinical use on formalin fixed paraffin embedded tissues. Diagn Mol Pathol 2008; 17:3-13.

23 Yamamoto G, Nannya Y, Kato M, et al. Highly sensitive method for genomewide detection of allelic composition in nonpaired, primary tumor specimens by use of affymetrix single-nucleotide-polymorphism genotyping microarrays. Am J Hum Genet 2007;81: 114-126.

24 Lefever S, Vandesompele J, Speleman F, et al. RTPrimerDB: the portal for real-time PCR primers and probes. Nucleic Acids Res 2009;37, Database issue D942-D945.

25 Zhao S, Fernald RD. Comprehensive algorithm for quantitative real-time polymerase chain reaction. J Comput Biol 2005;12:1047-1064.

26 Motzer RJ, Bander NH, Nanus DM. Renal-cell carcinoma. N Engl J Med 1996;335:865-875.

27 Liao D, Johnson R. Hypoxia: a key regulator of angiogenesis in cancer. Cancer Met Reviews 2007; 26:281-290.

28 Young AN, Master VA, Paner GP, et al. Renal epithelial neoplasms: diagnostic applications of gene expression profiling. Adv Anat Pathol 2008;15:28-38.

29 Lidgren A, Hedberg Y, Grankvist K, et al. Hypoxiainducible factor 1[alpha] expression in renal cell carcinoma analyzed by tissue microarray. Eur Urol 2006;50:1272-1277.

30 Gordan JD, Bertout JA, Hu C-J, et al. HIF-2a promotes hypoxic cell proliferation by enhancing c-Myc transcriptional activity. Cancer Cell 2007;11: 335-347.

31 Toschi A, Lee E, Gadir N, et al. Differential dependence of hypoxia-inducible factors1a and $2 \mathrm{a}$ on mTORC1 and mTORC2. J Biol Chem 2008;283: 34495-34499.

32 Moinzadeh P, Breuhahn K, Stutzer H, et al. Chromosome alterations in human hepatocellular carcinomas correlate with aetiology and histological grade-results of an explorative CGH meta-analysis. Br J Cancer 2005;92:935-941.

33 Patil MA, Gutgemann I, Zhang J, et al. Array-based comparative genomic hybridization reveals recurrent chromosomal aberrations and Jab1 as a potential target for $8 \mathrm{q}$ gain in hepatocellular carcinoma. Carcinogenesis 2005;26:2050-2057.

34 Bae MK, Ahn MY, Jeong JW, et al. Jab1 interacts directly with HIF-1alpha and regulates its stability. J Biol Chem 2002;277:9-12. 
35 Alimov A, Sundelin B, Wang N, et al. Loss of 14q31-q32. 2 in renal cell carcinoma is associated with high malignancy grade and poor survival. Int J Oncol 2004;25:179-185.

36 Mitsumori K, Kittleson JM, Itoh N, et al. Chromosome $14 \mathrm{q} \mathrm{LOH}$ in localized clear cell renal cell carcinoma. J Pathol 2002;198:110-114.
37 Louis DN. Molecular pathology of malignant gliomas. Ann Rev Pathol: Mech Dis 2006;1:97-117.

38 Jaffe ES. Pathology and Genetics of Tumours of Haematopoietic and Lymphoid Tissues. IARC Press; Oxford University Press (distributor): Lyon, Oxford, 2001.

Supplementary Information accompanies the paper on Modern Pathology website (http://www.nature.com/ modpathol) 